\title{
BIBLIOGRAPHIE SÉLECTIONNÉE DES OEUVRES DU PROF. JANEZ OREŠNIK
}

V bibliografiji je med sabo ločenih pet skupin:
A. SAMOSTOJNE PUBLIKACUIE;
B. ZNANSTVENI CLAANKI;
C. DRUGO;
Č. UREDNIŠKO DELO;
D. MENTORSTVO PRI DOKTORSKIH DELIF.

Znotraj posameznih skupin so dela razporejena časovno, znotraj posameznih let pa abecedno. Naslovi in podnaslovi avtorjevih samostojnih publikacij so tiskani polkrepko, serijske publikacije in zborniki, v katerih je objavljal znanstvene članke, v kurzivi. Opombe so pomanjšane in $\mathrm{s}$ tem ločene od ostalega opisa, ki ga v polkrepkem tisku zaključujejo opombe vsebinske narave, gesla. Na koncu bibliografije je kazalo. Avtorica je pripravila izbrano bibliografijo $\mathrm{v}$ sodelovanju $\mathrm{z}$ akademikom Janezom Orešnikom upoštevajoč njegov izbor.

\section{A. SAMOSTOJNE PUBLIKACIJE}

1965

1. Menjava sprege $\mathbf{v}$ zgodovini islandskega glagola : disertacija. Ljubljana : [J. Orešnik] 1965. IX, 414 str., loč. pag.

Doktorska disertacija. - Tipkopis

islandščina, zgodovinsko jezikoslovje, morfologija glagola

1971

2. Jezikovni priročnik za napovedovalce / J. Orešnik, F. Jakopin, D. Skubic. Ljubljana : Delavska univerza Boris Kidrič 1971. 91 str.

Ciklostil

slovenščina, uporabno jezikoslovje, javna raba, prevzete besede

1985

3. Studies in the phonology and morphology of Modern Icelandic : a selection of essays / edited by Magnús Pétursson. Hamburg : Buske 1985. 227 str.

Bibliografija: str. 217-218. - Kazalo. - Ponatis 12 že prej objavljenih člankov, na novo je avtor napisal bibliografijo, stvarno kazalo in kazalo uporabljenih rokopisov

islandščina, fonologija, morfologija 
4. Udeleženske vloge $\mathbf{v}$ slovenščini $=$ Semantic roles in Slovene. Ljubljana :

Slovenska akademija znanosti in umetnosti 1992. 237 str. (Dela SAZU, II. razred, Razred za filološke in literarne vede ; 37)

Bibliografija: str. 211-218. - Kazalo

slovenščina, semantika, udeleženske vloge

5. Slovenski glagolski vid in univerzalna slovnica $=$ Slovene verbal aspect and universal grammar. Ljubljana : Slovenska akademija znanosti in umetnosti 1994. 194 str. (Dela SAZU, II. razred, Razred za filološke in literarne vede ; 40) Bibliografija: str. 175-181. - Kazalo slovenక̌i̇ina, semantika, glagolski vid, slovnica

6. Uradi za jezik v Skandinaviji = Language committees in Scandinavia. Ljubljana : Slovenska akademija znanosti in umetnosti 1995. 145 str. (Dela SAZU, II. razred, Razred za filološke in literarne vede ; 42)

Bibliografija: str. 123-132. - Kazalo. - Ponatis poglavja o slovenskem uradu za jezik pod naslovom: Več glav več ve, več ljudi več vidi v dnevniku Republika 5. maja 1996, str. 9-10 Skandinavija, jezikovno načrtovanje, sociolingvistika, jeziki v stiku

1999

7. Krepke in šibke dvojnice v skladnji = Strong and weak variants in syntax. Ljubljana : Slovenska akademija znanosti in umetnosti 1999. 207 str. (Dela SAZU, II. razred, Razred za filološke in literarne vede ; 50) skladnja, teorija naravnosti, slovenščina, nemščina, skandinavski jeziki

2001

8. A predictable aspect of (morpho)syntactic variants = Predvidljiv vidik (obliko)skladenjskih dvojnic. Ljubljana : Slovenska akademija znanosti in umetnosti 2001. 243 str. (Dela SAZU, II. razred, Razred za filološke in literarne vede ; 58) Bibliografija: str. 231-235. - Kazalo skladnja, morfologija, teorija naravnosti, slovenščina, anglešcina, nemščina 
9. Naturalness in (morpho)syntax : English examples = Jezikovna naravnost $\mathbf{v}$ (obliko)skladnji : angleški zgledi. Ljubljana : Slovenska akademija znanosti in umetnosti 2004. 228 str. (Dela SAZU, II. razred, Razred za filološke in literarne vede ; 61) Bibliografija: str. 217-219. - Povzetek. - Kazalo skladnja, teorija naravnosti, anglešcina

\section{B. ZNANSTVENI ČLANKI}

10. Sravnitel'naja grammatika germanskix jazykov. Tom IV. Moskva 1966. - Linguistica (Ljubljana) 7, 1965, str. 169-175

Ocena knjige. - Povzetek v slovenščini

germanski jeziki, morfologija glagola

$$
1966-1968
$$

11. On N. Chomsky's strict subcategorization of verbs. - Linguistica (Ljubljana) 8, 1966-1968, str. 83-102

Povzetek v slovenščini

Chomsky, Noam, tvorbena slovnica, glagol

12. On the Perfect stem of the strong and the preterit-present verbs in late Proto-Germanic and in the old Germanic languages. - Linguistica (Ljubljana) 8, 1966-1968, str. 123-139

Bibliografija: str. 138. - Povzetek v slovenščini

primerjalno jezikoslovje, pragermanščina, morfologija, glagol

13. A philological miscellany on the Icelandic verbs kefja, ljá, cexa, skepja, sýsa. Linguistica (Ljubljana) 9, 1969, str. 49-52

Bibliografija: str. 51. - Povzetek v slovenščini islandščina, morfologija glagola

14. On some weak preterite subjunctives of otherwise strong verbs in Modern Icelandic. Arkiv för nordisk filologi (Lund) 86, 1971, str. 139-178 islandక̌čna, morfologija glagola 
15. On the phonological boundary between constituents of Modern Icelandic compound words. - Linguistica (Ljubljana) 11, 1971, str. 51-59

Bibliografija: str. 59. - Povzetek v angleščini in slovenščini

islandščina, besedotvorje, fonologija, zloženke

16. Four Modern Icelandic devoicing rules. - Linguistica (Ljubljana) 12, 1972, str. 137-156

Povzetek v angleščini in slovenščini

islandక̌čina, fonologija

17. Morphophonemic notes on the Modern Icelandic imperative singular. - Studies for Einar Haugen. Haag 1972, str. 450-459

Bibliografija: str. 459

islandščina, morfologija glagola, fonologija

18. On the epenthesis rule in Modern Icelandic. - Arkiv för nordisk filologi (Lund) 87,1972 , str. $1-32$

islandščina, fonologija

1973

19. Language particular rules and explanation in syntax / David M. Perlmutter, Janez Orešnik. - A Festschrift for Morris Halle. New York 1973, str. 419-459

Bibliografija: str. 458-459

slovenščina, skladnja, tvorbena slovnica

20. Old Icelandic consonant lengthening rule and Modern Icelandic infixation of /d/. - Linguistica (Ljubljana) 13, 1973, str. 229-261

Bibliografija: str. 259-260. - Povzetek v angleščini in slovenščini

islandšcina, morfologija, fonologija

1974

21. Einzelsprachliche Regeln und Erklärung in der Syntax / David M. Perlmutter, Janez Orešnik. - Syntax und generative Grammatik. Frankfurt am Main 1974, str. $161-230$

Bibliografija: str. 230

slovenščina, skladnja, tvorbena slovnica

1975

22. Moderne islandsk generativ fonologi - et eksempel. - Arsberetning for 1971-73 (København) 1975, str. 32-33

islandšcina, fonologija 
23. The Modern Icelandic $\mathrm{u}$-umlaut rule - The Nordic languages and modern linguistics 2. Stockholm 1975, str. 621-630

Bibliografija: str. 630 . - Avtorjevo sodelovanje v diskusiji po drugih predavanjih: o Kingovem predavanju na str. 67; o morfološkem delu konference na str. 174-175; o predavanju Labova na str. 236-237; o predavanju Catheya in Demersa na str. 419; o Wernerjevem predavanju na str. 792 islandščina, fonologija

1976

24. Inflection of modern Icelandic nouns, adjectives and adverbs. - Linguistica (Ljubljana) 16, 1976, str. 97-118

Bibliografija: str. 117-118. - Povzetek v anglěčini in slovenččini

islandščina, morfologija samostalnika, glagola, prislova

25. Über die Lautalternationen im neuisländischen Typus veggur. - Skandinavistik (Glückstadt) 6, 1976, str. 110-116

Bibliografija: str. 116

islandščina, fonologija

1977

26. Modern Icelandic u-umlaut from the descriptive point of view. - Gripla (Reykjavík) 2, 1977, str. 151-182

islandščina, fonologija

27. On the modern Icelandic palatalisation rule. - Dialectology and sociolinguistics. Essays in honour of Karl-Hampus Dahlstedt, 19 April 1977. Umeå 1977, str. 137-145 Bibliografija: str. 145. - Povzetek v angleščini

islandక̌cina, fonologija, nebnenje

28. Quantity in modern Icelandic / Janez Orešnik, Magnús Pétursson. - Arkiv för nordisk filologi (Lund) 92, 1977, str. 155-171

islandščina, fonetika, fonologija

29. Three modern Icelandic morphophonemic notes. - Sjötíu ritgerðir helgaðiar Jakobi Benediktssyni 20. júlí 1977. Reykjavík 1977, str. 621-626

Bibliografija: str. 625-626

islandščina, fonologija, morfologija

1978

30. The age and importance of the modern Icelandic word type klifr. - The Nordic languages and modern linguistics 3. Austin 1978, str. 468-471

Bibliografija: str. $470-471$

islandščina, fonologija, besedotvorje 
31. Inflection of modern Icelandic verbs and pronouns. - Linguistica (Ljubljana) 17, 1978, str. 91-122

Bibliografija: str. 121-122. - Povzetek v angleščini in slovenščini islandščina, morfologija glagola in zaimkov

32. The modern Icelandic epenthesis rule revisited. - Arkiv för nordisk filologi (Lund) 93, 1978, str. 166-173

Bibliografija: str. 173. - Povzetek v angleščini islandščina, fonologija

33. Modern Icelandic preaspiration from the phonological point of view. - Linguistica (Ljubljana) 18, 1978, str. 141-166

Bibliografija: str. 165-166. - Povzetek v angleščini in slovenščini islandščina, fonologija, preaspiracija

34. On the modern Icelandic i-umlaut rule. - General linguistics (University Park, Pa.) 18,1978 , str. $181-200$

Bibliografija: str. 199-200. - Porzetek v angleščini islandščina, fonologija, morfologija

35. On the pronunciation of modern Icelandic rövl(a) and slafneskur. - Íslenskt mál (Reykjavík) 1, 1979, str. 225-232

Bibliografija: str. 232. - Povzetek v angleščini

islandščina, fonologija, morfologija

36. Stødet i rigsdansk morfologi. - Danske Studier. København 1979, str. 123-129

Bibliografija: str. 129

danščna, morfologija

1980

37. On the dental accretion in certain 2nd p. sg. verbal forms of Icelandic, Faroese, and the old West Germanic languages. - Islenskt mál (Reykjavík) 2, 1980, str. 195-211

Bibliografija: str. 209-210

islandక̌čina, ferščina, fonologija, morfologija

38. On the lack of palatalisation before -end-in the plural of Icelandic nominalised present participles such as leikandi. - Linguistica (Ljubljana) 20, 1980, str. 245-259 Bibliografija: str. 257-258. - Povzetek $v$ angleščini in slovenščini islandščina, fonologija 
39. On the modern Icelandic clipped imperative. - The Nordic languages and general linguistics. Oslo 1980 , str. 305-314

Bibliografija: str. 311-314

islandščna, fonologija, morfologija

40. Um stýfðan boðhátt í íslensku. - Skima (Reykjavík) 3, 1980, str. 7-9

islanđščina, morfologija, glagol, velelnik

1981

41. On some Icelandic irregular imperative singular forms. - Afmæliskveðja til Halldórs Halldórssonar 13. júlí 1981. Reykjavík 1981, str. 211-218

Bibliografija: str. 217-218

islanđšcina, fonologija, morfologija

1983

42. An old Icelandic dialect feature: iæ for æ. - Gripla (Reykjavík) 5, 1983, str. 183-196

Bibliografija: str. 195-196

islanđక̌čina, stara islandక̌čina, narečja, fonologija

1984

43. Clitics are linguistic signs of excellent quality, or the origin of obligatory pronominal subjects in Germanic languages. - Wiener Linguistische Gazette. Supplement Beiheft 3. Wien 1984, str. 185-188

Bibliografija: str. 188

germanski jeziki, slovnica, naslonke, osebek

44. Icelandic imperative singular: some innovations. The Nordic languages and modern linguistics 5. Århus 1984, str. 337-341

Bibliografija: str. 341. - Ponatis v zborniku Eastern European Contributions to Scandinavian Linguistics. Oslo 1997, str. 62-67

islanđščina, fonologija, morfologija

45. The origin of the cliticness of the West Germanic definite article: the case of Beowulf. - Linguistica (Ljubljana) 24, 1984, str. 383-389

Bibliografija: str. 388-389. - Povzetek v slovenščini

zahodnogermanski jeziki, stara angleška književnost 
46. The obligatorium of unemphatic pronoun subjects in Germanic languages. Filologija (Zagreb) 14, 1986, str. 261-269

Bibliografija: str. 268-269

germanski jeziki, slovnica, naslonke, osebek

47. On the unemphatic pronoun subject of the Icelandic imperative. The Nordic languages and modern linguistics 6. Helsinki 1987, str. 301-309

Bibliografija: str. 308-309

islandక̌čina, morfologija, velelnik, osebek

1988

48. Modern Icelandic vowel quantity revisited. Yugoslav general linguistics. Amsterdam 1988, str. 227-240

Bibliografija: str. 240

islandščina, fonologija

49. Die neuisländische Vokalquantität aus historischer Sicht. Arbeiten zur Skandinavistik. Frankfurt am Main 1989, str. 46-55

Bibliografija: str. 54-55.

islandక̌̌ina, fonologija, zgodovinsko jezikoslovje

50. Die neuisländische Vokalquantität - ein neuer Versuch der Beschreibung. ÜberBrücken. Festschrift für Ulrich Groenke zum 65. Geburtstag. Hamburg 1989, str. $39-55$

Bibliografija: str. 53-55

islandక̌̌ina, fonologija

51. Introduction to the subsequent three papers in the present volume / Janez Orešnik ... [et al.]. - Linguistica (Ljubljana) 30, 1990, str. 5-12

Bibliografija: str. 11. - Povzetek v slovenščini

germanski jeziki, znanstveno raziskovanje, metodologija

52. Main vs. subordinate clauses: simple or complex? - Razprave SAZU, II. razred, Razred za filološke in literarne vede (Ljubljana) 13, 1990, str. 117-127

Bibliografija: str. 126. - Povzetek v slovenščini

క̌vedščina, skladnja 
53. Periphrasen sind verstärkte Konstruktionen. Spielarten der Natürlichkeit Spielarten der Ökonomie. Bochum 1990, str. 85-99

Bibliografija: str. 99

germanski jeziki, slovnica, teorija naravnosti

1992

54. Expanded tenses in the Old English Orosius: a strengthened construction / Janez Orešnik, Frančiška Trobev̌šk-Drobnak. - Language and civilization. A concerted profusion of essays and studies in honour of Otto Hietsch. Frankfurt am Main 1992, str. 146-161

Bibliografija: str. 161

stara angleščina, skladnja, glagol

55. Relative clauses are relatively simple. - The Nordic languages and modern linguistics 7. Tórshavn 1992, str. 75-92

Bibliografija: str. 91-92

norveški jeziki, skladnja

1995

56. Syntaktischer Wandel und Natürlichkeit in der Forschung slowenischer Linguisten. - Natürlichkeitstheorie und Sprachwandel = Teorija naravnosti in jezikovno spreminjanje. Bochum 1995, str. 253-261

Bibliografija: str. 260-261

slovenščina, teorija naravnosti, skladnja

1996

57. Unaccented pronominal subjects in the Germanic languages. - Suvremena lingvistika. - (Zagreb) 41/42, 1996, str. 489-496

Bibliografija: str. 495-496

germanski jeziki, zaimek, osebek

1998

58. Zum Passiv in skandinavischen Sprachen. Zbornik referatov II. mednarodnega simpozija o teoriji naravnosti 23. do 25. maj $1996=$ Sammelband des II. internationalen Symposions zur Natürlichkeitstheorie 23. bis 25. Mai 1996. Maribor 1998, str. 13-24 Bibliografija. - Povzetek v slovenščini

skandinavski jeziki, trpnik, teorija naravnosti, skladnja 
59. Naturalness: the English $s$-genitive and of-phrase. - Studia Anglica Posnaniensia (Poznań) 34, 1999, str. 191-200

Bibliografija: str. 199-200

angleščina, teorija naravnosti, skladnja, rodilnik

2000

60. Naturalness: negators in standard French. - Papiere zur Linguistik (Tübingen) $62 / 63,2000$, str. $39-48$

Bibliografija: str. $47-48$

francoščina, teorija naravnosti, nikalnice

61. Naturalness: the preterite and present perfect tenses in German. - Linguistics and language studies: exploring language from different perspectives. - Ljubljana 2000, str. $21-43$

nemščina, skladnja, teorija naravnosti, pretekli časi

62. Naturalness: the scale formats $>\operatorname{sem}(+/-\mathrm{A},-\mathrm{A})$ and $>\operatorname{sem}(+/-\mathrm{A},+\mathrm{A}) .-$ Linguistica (Ljubljana) 40, 2000, str. 237-262

Bibliografija: str. 262. - Povzetek v slovenščini

skladnja, teorija naravnosti

63. Naturalness applied to Slovenian (morpho)syntax. - Wiener slavistisches Jahrbuch (Wien) 47, 2001, str. 135-158

Bibliografija: str. 157-158

slovenščina, skladnja, oblikoskladnja, teorija naravnosti

64. Naturainess expressed in sEm-values. - Linguistica (Ljubljana) 41, 2001, str. 5-19 Bibliografija: str. 18-19

skladnja, teorija naravnosti

65. Naturalness expressed in sYm-values. - Folia Linguistica (Berlin) 35, 2001, str. 321-335

Bibliografija: str. 334-335

skladnja, teorija naravnosti

66. Naturalness: the passive in the mainland Scandinavian languages. Sprachtypologie und Universalienforschung (Berlin) 54, 2001, str. 26-34

Bibliografija: str. 34

skanđinavski jeziki, teorija naravnosti, trpnik 
67. Naturalness: some Slovenian (morpho)syntactic examples. - Slovenski jezik $=$ Slovene linguistic studies (Ljubljana) 3, 2001, str. 3-31

Bibliografija: str 29-30. - Povzetek v slovenščini in angleščini slovenščina, teorija naravnosti, oblikoskladinja

68. Slovenski glavni števniki v luči teorije naravnosti. - Slavistična revija (Ljubljana) 49,2001 , str. $237-246$

Bibliografija: str. 246. - Povzetek v angleščini

slovenšcina, teorija naravnosti, skladnja, oblikoskladnja, števnik

2002

69. Naturalness in English: some (morpho)syntactic examples. - Linguistica (Ljubljana) 42, 2002, str. 143-160

Bibliografija: str. 159. - Povzetek v slovenščini in angleščini

skladnja, teorija naravnosti, angleščina

$$
\text { 2002-2003 }
$$

70. Naturalness in English: the infinitive clause. - Klagenfurter Beiträge zur Sprachwissenschaft (Wien) 28/29, 2002-2003, str. 147-160 angleščina, teorija naravnosti, skladnja, nedoločniški polstavek, nedoločnik

71. Naturalitat lingüística en català: concordança amb l'objecte. - Verba Hispanica (Ljubljana) 11, 2003, str. 69-77

Bibliografija: str. 76-77. - Povzetek v slovenščini

katalonščina, teorija naravnosti, skladnja, ujemanje s predmetom

72. Naturalness in English: (A) The genitive, (B) The pronouns. - Linguistica (Ljubljana) 43, 2003, str. 119-140

Bibliografija: str. 139

angleščina, teorija naravnosti, skladnja, rodilnik, zaimek

73. Naturalness: some English (morpho)syntactic examples. - Studia Anglica Posnaniensia (Poznań) 39, 2003, str. 77-101

Bibliografija: str. 100-101

anglešcina, teorija naravnosti, oblikoskladnja

74. Naturalness: some Norwegian (morpho)syntactic examples. - Norsk lingvistisk tidsskrift (Oslo) 21, 2003, str. 57-70

Bibliografija: str. 69-70

norveščina, tvorbena slovnica, oblikoskladnja 
C. DRUGo

\section{7}

75. Vabilo $\mathrm{k}$ preučevanju transformacijske generativne slovnice. - Jezik in slovstvo (Ljubljana) 12, 1967, str. 83-86

splošno jezikoslovje, tvorbena slovnica

1968

76. O besedah in pojmih narod, nacija ipd. - Jezik in slovstvo (Ljubljana) 13, 1968, str. 34-35

slovenščina, semantika

1970

77. Horace G. Lunt: Attempt at a generative description of the Slovene verb. Wiesbaden 1966. - Linguistica (Ljubljana) 10, 1970, 121-129

Ocena knjige

slovenščina, tvorbena slovnica, glagol

78. O aksiomatski teoriji naravnih jezikov. - Ljubljana : Institut Jožef Stefan 1970. 18 str. (Nuklearni Institut Jožef Stefan ; P-260)

teorija naravnosti, tvorbena slovnica, aksiomi

1971

79. Allan R. Keiler: A phonological study of the Indo-European laryngeals. The Hague 1970. - Germanistik (Tübingen) 12, 1971, str. 462

Prikaz knjige

fonologija, indoevropski jeziki, primerjalno jezikoslovje

80. Language particular rules and explanation in syntax / David M. Perlmutter, Janez Orešnik. Cambridge ; Massachusetts 1971. 80 str. loč. pag. (Language research report ; No. 5)

Bibliografija: str. 79-80

slovenščina, skladnja, tvorbena slovnica

81. Novo v teoriji naravnih jezikov. - Prostor in čas (Maribor) 3, 1971, str. 154-165 Bibliografija: str. 165

naravni jeziki, semantika, tvorbena slovnica 
82. Formalizacija semantičnih definicij najmanjših jezikovnih enot s pomenom. Problemi semantike, sintakse in obravnave tekstov. Ljubljana 1972, str. 37-45

Bibliografija: str. 44-45

naravni jeziki, semantika

83. Formalizacija stavčnih pomenov. - Problemi semantike, sintakse in obravnave tekstov. Ljubljana 1972, str. 46-54

semantika, stavek, pomen stavka

84. O t. i. omejitvah v formalizirani slovnici naravnih jezikov. Ljubljana : Institut Jožef Stefan 1972. 13 str. (Institut Jožef Stefan ; P-280)

naravni jeziki, slovnica

85. O t. i. transformacijskem ciklu v sintaksi angleškega jezika. - Problemi semantike, sintakse in obravnave tekstov. Ljubljana 1972, str. 68-74

angleščina, skladnja, pretvorba

86. T. i. presupozicije v semantiki naravnih jezikov. - Problemi semantike, sintakse in obravnave tekstov. Ljubljana 1972, str. 55-67

semantika, naravni jeziki, presupozicija

87. Razlaganje sintaktičnih posebnosti / D. M. Perlmutter, J. Orešnik. V Ljubljani : Univerza 1973. 35 str. (Institut Jožef Stefan ; P-282) anglešcina, skladnja, pretvorba

1974

88. Generative grammar in Europe. Dordrecht 1973. - Linguistica (Ljubljana) 14, 1974, str. 95-102

Prikaz zbornika

splošno jezikoslovje, tvorbena slovnica

1975

89. Magnús Pétursson: Les articulations de l'islandais à la lumière de la radiocinématographie. Paris 1974. - General linguistics (University Park, Pa.) 15, 1975, str. $120-126$

Bibliografija: str. 125-126. - Ocena knjige

islandščina, fonologija 
90. Einar Haugen: The Scandinavian languages. Cambridge 1976. - General linguistics (University Park, Pa.) 18, 1978, str. 37-47

Prikaz knjige

skandinavski jeziki, zgodovina jezika

91. Magnús Pétursson: Drög aj hljóðkerfisfræði. Reykjavík 1978. - Nordic Linguistic Bulletin (Uppsala) 1978, 2, str. 22-29

Ocena knjige

islandščina, fonetika

92. Magnús Pétursson: Isländisch. Hamburg 1978. - Linguistica (Ljubljana) 18, 1978 , str. $261-264$

Ocena knjige

islandščina, učbenik

$$
1979
$$

93. Krajevno ime Laibach v Nemčiji. - Onomastica Jugoslavica (Zagreb) 8, 1979, str. 47-49 imenoslovje, krajevna imena, Laibach

94. Holandščina ali nizozemščina?. - Jezik in slovstvo (Ljubljana) 26, 1980, ov. III Ponatis v knjigi: B. Golob: Žive beside. Ljubljana 1982, str. 10 slovenščina, imena jezikov, imenoslovje

95. Rečno ime Laibach 'Ljubljanica'. - Jezik in slovstvo (Ljubljana) 26, 1980, str. 98 imenoslovje, rečna imena, Laibach

\section{$1983-1984$}

96. Slovenske breznaglasnice se vedejo predvsem kot proklitike. - Jezik in slovstvo (Ljubljana) 29, 1983-1984, str. 129

slovenščina, slovnica, naslonke

$1984-1985$

97. O desnem izpustu proklitično-enklitičnih naslonk. - Jezik in slovstvo (Ljubljana) $30,1984-1985$, str. $145-147$

slovenščina, slovnica, naslonke 
98. O desnem prilastku v slovenščini. - Jezik in slovstvo (Ljubljana) 30, 1984-1985, str. 242-243

Popravek k temu članku Jezik in slovstvo (Ljubljana) 31, 1985-1986, ov. III slovenščina, slovnica, prilastek

99. Einar Haugen: Die skandinavischen Sprachen. Hamburg 1984. - General linguistics (University Park, Pa.) 26, 1986, str. 68-69

Prikaz knjige

skandinavski jeziki, zgodovina jezika

100. O naslonskem nizu v knjižni slovenščini. - Jezik in slovstvo (Ljubljana) 31, 1986, str. 213-215

jezikoslovje, slovnica, slovenščina, knjižni jezik

101. Wolfgang U. Dressler: Morphonology. Ann Arbor 1985. - Linguistica (Ljubljana) 26,1986 , str. $185-192$

Prikaz knjige

morfonologija

$1986-1987$

102. O slovenskem glagolskem načinu. - Jezik in slovstvo (Ljubljana) 32, 1986-1987, str. $146-150$

slovenščina, slovnica, glagolski način

$$
1987-1988
$$

103. K izvoru slovarske enote pletnja. - Jezik in slovstvo (Ljubljana) 33, 1987-1988, str. 62

slovenščina, etimologija, slovarji

1992

104. O neki skladenjski posebnosti slovenskih svojilnih pridevnikov. - Miklošičev zbornik. Ljubljana 1992, str. 263-267

Bibliografija: str. 267. - Povzetek

slovenščina, skladnja, morfologija, samostalniška zveza

1996

105. Nauk novejše slovenistike o povedkovem prilastku. - Razprave SAZU, II. razred, Razred za filološke in literarne vede (Ljubljana) 15, 1996, str. 255-267

Povzetek v slovenščini

slovenščina, slovnica, skladnja, povedkov prilastek 
106. O primerjalni metodi $\mathrm{v}$ jezikoslovju. - Zbornik prve mednarodne konference Veneti $v$ etnogenezi srednjeevropskega prebivalstva. Ljubljana 2001, str. 109-111 primerjalno jezikoslovje, inđoevropski jeziki, primerjalna metoda

2003

107. Introduction / J. Orešnik, Donald F. Reindl. - Slovenian from a typological perspective. Sprachtypologie und Universalienforschung 56. Ljubljana 2003, str. 153-164 slovenščina, tipologija, bibliografija

\section{Č. UREDNIŠKO DELO}

2000

108. Linguistics and language studies : exploring language from different perspectives / edited by Irena Kovačič, Milena Milojević-Sheppard, Silvana Orel-Kos and Janez Orešnik. - Ljubljana : Filozofska fakulteta 2000. - 204 str. jezikoslovje, zbornik

109. Razprave SAZU, II. razred, Razred za filološke in literarne vede XVII / urednik Jože Toporišič, souredniki Kajetan Gantar, Franc Jakopin, Janez Orešnik. Ljubljana : Slovenska akademija znanosti in umetnosti 2000 slovenččina, zbornik

2003

110. Slovenian from a typological perspective / editors: Janez Orešnik \& Donald F. Reindl. - Berlin : Akademie Verlag 2003. Str. 153-322 (Sprachtypologie und Universalienforschung = Language typology and universals, vol. 56, issue 3) slovenščina, tipologija, zbornik

D. MENTORSTVO PRI DOKTORSKIH DELIH

1990

111. Trobevšek Drobnak, Frančiška: Skladnja staroangleških glagolov s predpono ge- v primerjavi s skladnjo staroangleških glagolov brez predpone : doktorska disertacija. Ljubljana : [F. Trobevšek-Drobnak] 1990. $217 \mathrm{f}$. 
112. Milojević Sheppard, Milena: Oblikoslovno-skladenjske razširitve pri prevajanju iz angleščine v slovenščino kot prototipični odziv na zapletenost izvirnika : doktorska disertacija. Ljubljana : [M. Milojević Sheppard] 1991. 593 str., 96, 109 str. pril.

113. Teržan-Kopecky, Karmen : Prihodnjik kot skladenjska okrepitev v nemščini diahroni in sinhroni vidiki : doktorska disertacija. V Ljubljani : [K. Teržan] 1991. $343 \mathrm{f}$.

114. Kovačič, Irena: Jezikoslovni pogled na podnaslovno prevajanje televizijskih oddaj : doktorska disertacija. Ljubljana : [I. Kovačič] 1992. VI, 290, 187 str.

1993

115. Šuštaršič, Rastislav: Kontrastivna analiza angleške in slovenske stavčne intonacije : doktorska disertacija. Ljubljana : [R. Šuštaršič] 1993. 253, [42] f.

1995

116. Petrič, Teodor: Naklonski členki v nemščini : doktorsko delo. Ljubljana : [T. Petrič] 1995. 727 str.

1997

117. Zorman, Marina: Nekateri strukturalno-funkcionalni odnosi med členi sinonimnih vrst $v$ slovenščini : doktorska disertacija. Ljubljana : [M. Zorman] 1997. $347 \mathrm{f}$.

2003

118. Dobrovoljc, Helena: Preverba teorije o jezikovni naravnosti ob slovenskem (obliko)skladenjskem gradivu : doktorska disertacija. Ljubljana : [H. Majcenovič] 2003. $321 \mathrm{f}$.

2004

119. Bizjak, Aleksandra: Jezikoslovne osnove pridige kot žanra : doktorska disertacija. Ljubljana : [A. Bizjak] 2004. VIII, 276 str. 
aksiomi 78

angleščina $8,9,59,69,70,72,73,85,87$

besedotvorje 15,30

bibliografija 107

Chomsky, Noam 11

danščina 36

etimologija 103

ferščina 37

fonetika 28,91

fonologija $3,15,16,17,18,20,22,23,25,26,27,28,29,30,32,33,34,35,37,38$, $41,42,44,48,49,50,79$

francoščina 60

germanski jeziki $10,43,46,51,53,57$

glagol 11, 12, 40, 54, 77

glagolski način 102

glagolski vid 5

imena jezikov 94

imenoslovje 93, 94, 95

indoevropski jeziki 79, 106

islandščina $1,3,13,14,15,16,17,18,19,20,22,23,24,25,26,27,28,29,30,31$,

$32,33,34,35,37,38,39,40,41,42,44,47,48,49,50,89,91,92$

javna raba 2

jeziki v stiku 6

jezikoslovje 100,108

jezikovno načrtovanje 6

katalonščina 71

knjižni jezik 100

krajevna imena 93

Laibach 93, 95

metodologija 51

morfologija $8,12,20,29,34,35,36,37,39,40,41,44,47,101,103$

morfologija glagola $1,3,10,13,14,17$

morfologija glagola in zaimkov 31

morfologija samostalnika, glagola, prislova 24

naravni jeziki $81,82,84,86$

narečja 42

naslonke $43,46,96,97$

nebnenje 27

nedoločnik 70

nedoločniški polstavek 70

nemščina $7,8,61$ 
nikalnice 60

norveščina 74

norveški jeziki 55

oblikoskladnja $63,67,73,74$

osebek 43, 46, 47, 57

pomen stavka 83

povedkov prilastek 105

pragermanščina 12

preaspiracija 33

presupozicija 86

pretekli časi 61

pretvorba 85,87

prevzete besede 2

prilastek 98

primerjalno jezikoslovje 12, 79, 106

rečna imena 95

rodilnik 59,72

samostalniška zveza 104

semantika $4,5,76,81,82,83,86$

Skandinavija 6

skandinavski jeziki $7,58,66,90,99$

skladnja $7,8,9,19,21,52,54,55,56,58,59,61,62,63,64,65,68,69,70,71,72$, $73,74,75,76,77,78,79,80,85,87,103,105$,

slovarji 103

slovenščina $2,4,5,7,8,19,21,56,63,67,68,76,77,80,94,96,97,98,100,102$, $103,105,107,109$

slovnica $5,43,46,53,84,96,97,98,100,102,105,110$

sociolingvistika 6

splošno jezikoslovje 75,88

stara angleščina 54

stara angleška književnost 45

stara islandščina 42

stavek 83

števnik 68

švedščina 52

teorija naravnosti $7,8,9,53,56,58,59,60,61,62,63,64,65,66,67,68,69,70,71$, $72,73,78$

tipologija 107,110

trpnik 58,66

tvorbena slovnica $11,19,21,74,75,77,78,80,81,88$

učbenik 92

udeleženske vloge 4

ujemanje s predmetom 71

uporabno jezikoslovje 2 
velelnik 40,47

zahodnogermanski jeziki 45

zaimek 57,72

zbornik 108, 109, 110

zgodovina jezika 90,99

zgodovinsko jezikoslovje 1, 49

zloženke 15

znanstveno raziskovanje 51

Ana Juvančič Mehle 